\title{
The Prognostic and Predicting Roles of Tumor-Infiltrating Lymphocytes in Breast Cancer: A Meta-Analysis
}

\author{
Ezzeldin M. Ibrahim ${ }^{*}, 1$, Meteb Al-Foheidi ${ }^{2}$, Mubarak M. Al-Mansour ${ }^{2}$, Ghieth A Kazkaz ${ }^{1}$ and \\ Tahir E. Yunus ${ }^{1}$ \\ ${ }^{1}$ Oncology Center of Excellence, International Medical Center, PO Box 2172, Jeddah 21451, Kingdom of Saudi Arabia \\ ${ }^{2}$ Princess Noorah Oncology Center, King Abdulaziz Medical City, PO BOX 9515, Jeddah 21423, Kingdom of Saudi \\ Arabia
}

\begin{abstract}
Background: The relationship between lymphocyte infiltrates (LIs) and breast cancer outcome remains controversial. We performed this meta-analysis to elucidate the relationship.

Methods: A literature search identified 21 eligible studies.

Results: 16,097 patients were included. Multivariate analyses data for patients with unspecified receptors status showed that rich LIs expression was associated with $52 \%$ (hazard ratio [HR] $=0.48 ; 95 \%$ confidence interval [CI], 0.30-0.77), and $29 \%(\mathrm{HR}=0.71 ; 95 \% \mathrm{CI}, 0.63-0.80)$ reduction in the risk of relapse and death, respectively. In the neoadjuvant setting, rich LIs predicted a $28 \%$ increase in complete pathological response rate. The prognostic and predictive utility of rich LIs was restricted to patients with estrogen receptor negative (ER-) or triple negative disease. Only rich CD8+ T cells tumors demonstrated clinical utility.

Conclusion: LIs significantly correlated to outcome predominantly in ER- tumors. Integrating immunotherapy with conventional therapy may warrant future research in breast cancer.
\end{abstract}

Keywords: Breast cancer, lymphocyte, prediction, prognosis.

\section{INTRODUCTION}

Several studies suggest that the immune response of the host plays pivotal roles in tumorigenesis, tumor development, disease progression, and subsequent metastasis $[1,2]$. Moreover, the intensity of tumoral immune response influences the efficacy of cancer therapy, and favorably affects the clinical outcome in several solid tumors [1, 3-5]. Conversely, the presence of certain T-cell subsets such as the expression of regulatory $\mathrm{T}$ cell-specific forkhead box transcription factor (FOXP3) have shown negative prognostic effect [6].

Lymphocyte infiltrates (LIs) in breast cancer is an intriguing phenomenon that predominates in aggressive breast cancers including estrogen receptor negative (ER-) tumors [7], high-grade tumors [8, 9], basal-like tumors [10], and BRCA1-associated cancers [11]. Also shown is the high expression of LIs in the medullary histological type [12], a subset with a known favorable prognosis.

Nevertheless, the literature concerning the characterization of LIs and their prognostic utility in breast cancer has been inconsistent. These findings could be explained by the substantial diversity in patient population, description of

*Address correspondence to this author at the Oncology Center of Excellence, International Medical Center, PO Box 2172, Jeddah 21451, Kingdom of Saudi Arabia; Tel: +966505-82-5953; Fax: +96652-650-9141;

E-mail: ezzibrahim@imc.med.sa
LIs, the immunological response involved, and the methods and criteria used to qualify the immune response [13].

To the best of our knowledge, no published meta-analysis has examined the clinical utility of LIs in patients with breast cancer. The lack of such data and the conflicting outcomes of reported studies have prompted the current meta-analysis.

\section{METHODS}

\section{Search Strategy}

Between January 1985 and April 2013, we identified studies of interest by first conducting an electronic literature search of the following databases: MEDLINE, EMBASE, and the Cochrane Library. We also searched for relevant abstracts in conference proceedings of the American Society of Clinical Oncology and the European Society for Medical Oncology.

We used exploded Medical Subject Heading terms or key words terms 'breast', 'cancer', and 'neoplasm'. The terms were combined with 'infiltrate', 'inflammatory', 'immune response', 'lymphocyte', 'B cell', 'T cell', 'CD20', 'CD3', CD4', and 'CD8'. In the second step, we combined these keywords using the Boolean operator 'and' with 'prognosis', 'prediction', and 'pathologic response'. In addition, we manually reviewed the reference lists of relevant studies to identify additional pertinent articles. 


\section{Selection Criteria}

We included all studies that met the following criteria: (i) published in English language between January 1985 and April 2013; (ii) included patients of any age and with any stage of breast cancer; (iii) investigated the prognostic and/or the predictive role of LIs or its immunohistochemistry (IHC) markers in breast cancer tumors; (iv) reported hazard ratio (HR) for relapse-free survival (RFS) or overall survival (OS), or reported the odds ratio (OR) for complete pathological response (pCR), or reported adequate data allowing such outcomes to be computed; and (v) published as original articles (no case reports, case series, reviews, comments, letters, or editorials). When two or more articles reported duplicate data, we included only the most recent data, the study with the longer follow-up, or the most relevant study. However, we included studies that have used the same data set but examined different LIs markers. We excluded studies that only examined the effects of therapy on LIs expression.

\section{Data Extraction}

Four authors (EI, MA, MMA, GAK) independently inspected each item identified by the search and applied the inclusion/exclusion criteria. All authors reviewed the articles completely and discussed the data intended for extraction.

We used a standardized Microsoft Excel sheet to abstract data for each study that met inclusion criteria. Extracted data included the following fields: first author's last name, publication year, brief study description, study design (prospective versus retrospective), disease stage (early versus metastatic), number of patients, median age, histology, receptors status, median follow-up, method used to determine LIs, anatomical location of LIs, and outcome measures. We extracted information concerning blinding versus open interpretation of LIs, however as most of the included studies were of retrospective nature, therefore a study quality framework was not utilized.

\section{Outcome Measures}

The outcome measures extracted or computed were the HRs and its $95 \%$ confidence interval (CI) for RFS or OS. We also extracted or calculated the $\mathrm{OR}$ for the $\mathrm{pCR}$ in neoadjuvant studies. Because studies have used different definitions for LIs, the HR or OR was considered as the risk ratio between tumors with rich versus those with no/low LIs expression.

\section{Statistical Analyses}

The pooled estimates of the HR or OR and their CIs were the primary end points of the meta-analysis. We calculated unreported HR or OR and its 95\% CI using the procedure proposed by Tierney et al. [14], that is based on the method reported by Parmar et al. [15] Where appropriate, we also used the built-in calculator of the Review Manager for Windows software version 5.2.3 to compute pertinent data (The Cochrane Collaboration, Oxford, UK). We added 0.5 to a cell frequency of zero to calculate the estimates. In studies that reported a univariate and a multivariate analysis for the same comparison, we only used the latter.

We assessed the heterogeneity of the results by inspecting the graphical presentations and by calculating a $X^{2}$ test of heterogeneity and the $I^{2}$ statistic of inconsistency [16, 17]. Statistically significant heterogeneity was defined as a $X^{2} \mathrm{P}$ value less than 0.1 or an $I^{2}$ statistic greater than $50 \%$. The pooled estimates of HR or OR, together with the associated $95 \% \mathrm{CI}$, were obtained using the DerSimonian and Laird random-effects model [18]. We performed metaregression analysis to determine to what extent the effects of clinical variables could explain any demonstrated heterogeneity. The dependent variable was the $\operatorname{lnHR}$ or InOR, where appropriate, weighted for the inverse of variance to perform weighted least-square linear regression. We first conducted a univariate regression analysis for each relevant variable followed by a multivariate regression analysis including only variables found significant in the univariate analysis. We assumed the data to be missing at random, therefore, observed study characteristics were used to impute missing data by means of multiple imputations [19].

We performed subgroup analyses to assess the potential contributions of various clinicopathological variables to the main outcome. Studies that did not provide sufficient data to permit estimating relevant parameters in a subgroup analysis were excluded from that statistical pooling. Any comparison/analysis that was derived from a single study was not reported. A funnel plot estimating the precision of trials (plots of logarithm of the HR or OR against its inverse standard error) was examined for asymmetry to determine publication bias [20]. Publication bias was also quantified by the regression asymmetry test by Egger [20].

All statistical tests were two-sided. We used Comprehensive Meta-analysis Software for all pooled estimates (Biostat, version 2.2.064, Englewood New Jersey, USA). For meta-regression analyses, we used the SPSS statistical package (IBM SPSS Statistics for Windows, version 20.0., New York, USA).

\section{RESULTS}

We identified 437 potentially relevant articles (Fig. 1). After exclusion of duplicate references, nonrelevant literature, and those that did not satisfy the inclusion criteria, 21 candidate articles were included. Tables $\mathbf{1}$ and $\mathbf{2}$ show the abstracted data of the included studies. Eighteen studies evaluated the prognostic utility of LIs on RFS and/or OS [13, 21-37], and 5 studies examined the value of LIs in predicting pCR [21, 34, 38-40] (two of those 5 studies also examined survival [21,34].

Calabro et al. [22] used two data sets in a single report (155 breast tumor samples from the Medical University of Graz, and 1044 patients with invasive ductal carcinoma [IDC] from a publically available data set). Denkert et al. [38], classified their patients into two cohorts (i. e., training and validation sets (214, and 840 patients, respectively)).

There were 16,097 patients in the included studies with a median age of 55 years $(95 \%$ CI, 49- 58.9 years) as abstracted from the studies' reported median age. 


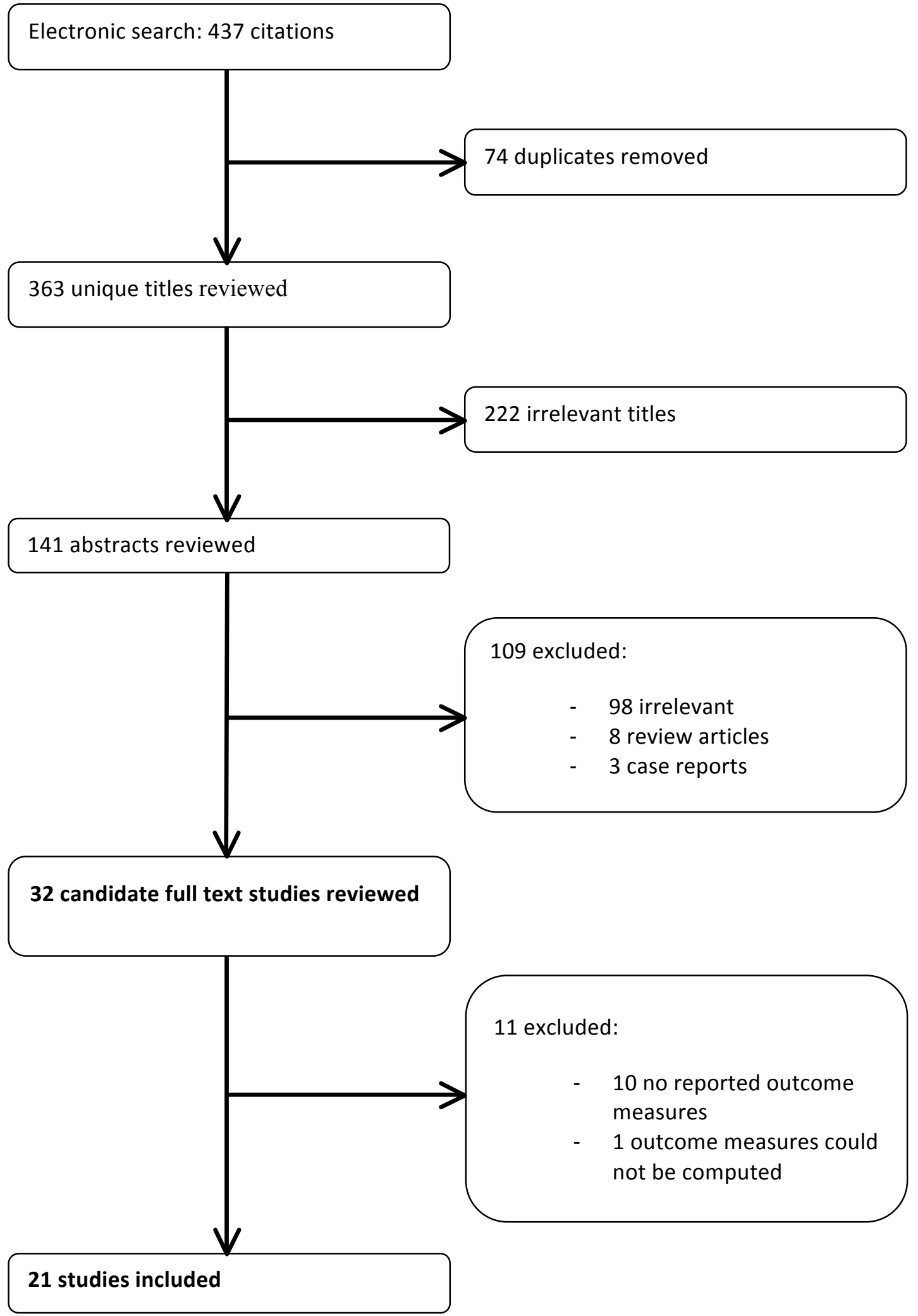

Fig. (1). Flowchart of literature search and the selection of the 21 included studies.

Approximately 100 patients had metastatic disease, while the remaining had non-metastatic or locally advanced breast cancer. In patients analyzed for survival outcome, the median percentage $(95 \% \mathrm{CI})$ of patients with positive estrogen receptor $(\mathrm{ER}+)$, negative estrogen receptor (ER-), and positive HER2 (HER2+) were 65\% (50-73\%), 35\% (27$50 \%)$, and $17 \%(13-27 \%)$, respectively. The corresponding percentages for patients in the neoadjuvant setting were $13 \%$ (0-68\%), 87\% (32-100\%), and 32\% (23-100\%), respectively. 
Table 1. Clinical characteristics of studies evaluating the effects of lymphocyte infiltrates on relapse-free and overall survival (16 studies).

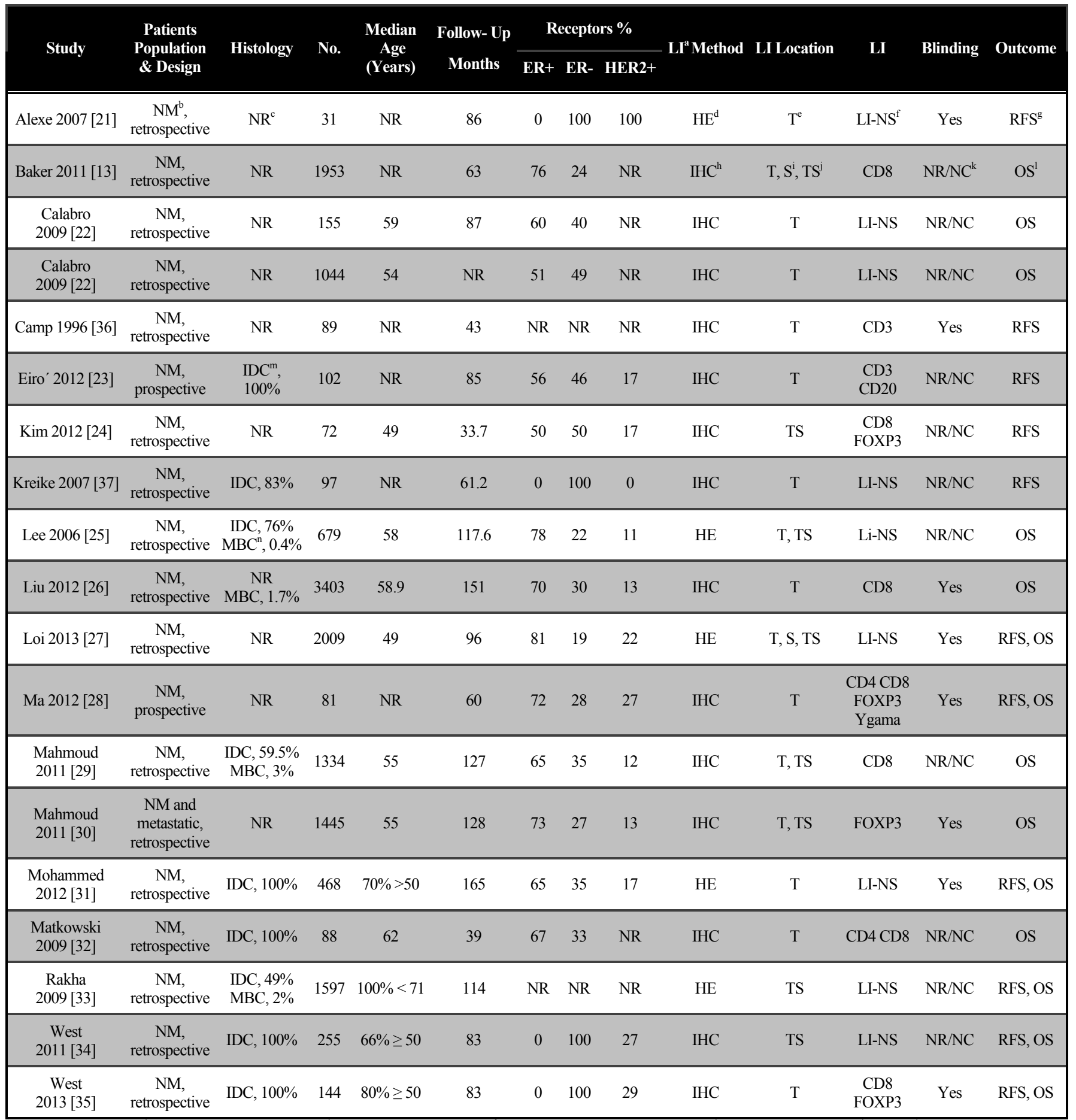

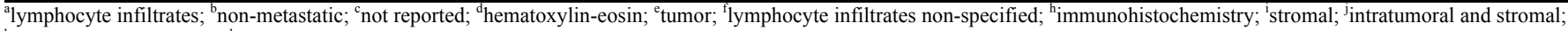
${ }^{k}$ not reported or not clear; ${ }^{1}$ overall survival; ${ }^{m}$ invasive ductal carcinoma; ${ }^{n}$ medullary carcinoma.

For studies reporting on histological subtypes, most patients had IDC (ranging from $59.5 \%$ to $100 \%$ ), while medullary breast cancers were present in approximately 232 patients including 132 reported by Rakha et al. [33]. The median follow-up, when reported, was 96.5 months $(95 \% \mathrm{CI}$, 63-127 months). Only three studies were prospective [23, $28,39]$, whereas in 9 studies, assessors of LIs were blinded from patients' outcome $[21,26,27,30,31,35,36,38]$. In the remaining 10 studies, blinding was not reported or it was not clear if was implemented.

\section{Risk of Bias}

The funnel plots for studies that tested the effects of LIs on RFS or OS showed no asymmetry and the Egger linear regression tests were not significant, indicating no evidence of significant publication bias (2-sided $\mathrm{P}$ values, 0.81 and 
Table 2. Clinical characteristics of studies evaluating the effects of lymphocyte infiltrates on complete pathological response rate (5 studies).

\begin{tabular}{|c|c|c|c|c|c|c|c|c|c|c|c|c|}
\hline Study & $\begin{array}{c}\text { Patients } \\
\text { Population \& } \\
\text { Design }\end{array}$ & Histology & No. & $\begin{array}{c}\text { Median } \\
\text { Age } \\
\text { (Years) }\end{array}$ & ER+ & ER- & Her2+ & $\mathbf{L I}^{\mathrm{a}}$ Method & LI Location & LI & Blinding & $\begin{array}{c}\text { Overall } \\
\text { pCR } \%^{b}\end{array}$ \\
\hline Denkert 2010 [38] & $\mathrm{NM}$, retrospective & NR & 1058 & NR & NR & NR & NR & $\mathrm{IHC}^{\mathrm{h}}$ & $\mathrm{T}, \mathrm{TS}^{\mathrm{i}}$ & LI-NS $^{j}$ & Yes & 13 \\
\hline Ono 2012 [39] & NM, prospective & NR & 180 & 52 & 26 & 74 & 23 & $\mathrm{IHC}$ & $\mathrm{S}^{\mathrm{k}}$ & CD4 & $\mathrm{NR} / \mathrm{NC}^{1}$ & 32 \\
\hline Yamaguchi 2012 [40] & $\mathrm{NM}$, retrospective & NR & 68 & $60 \% \geq 50$ & 68 & 32 & 38 & $\mathrm{IHC}$ & TS & LI-NS & $\mathrm{NR} / \mathrm{NC}$ & 24 \\
\hline
\end{tabular}

0.16 , respectively). On the contrary, the funnel plot for studies that assessed the predictive value of LIs on pCR showed asymmetry and the Egger linear regression test was significant, indicating publication bias (2-sided $\mathrm{P}$ value $=$ 0.026).

\section{Analysis of Pooled Estimates}

In most of, we found heterogeneity upon using the fixedeffects models (data not shown). Therefore, we based all analyses on random-effects models as described in the methodology section.

\section{ANALYSIS OF RFS (TABLE 3)}

\section{Multivariate Analysis}

We first examined the utility of any detention used for rich LIs to prognosticate RFS for all patients regardless of their tumor receptors status (ER-not specified, ER-NS), only using data that were based on multivariate analysis in the original studies. Data for this pooled measure were abstracted or computed from seven studies (Table 3), and displayed that rich LIs was associated with a $52 \%$ reduction in the risk of relapse $(\mathrm{HR}=0.48 ; 95 \% \mathrm{CI}, 0.30-0.77, \mathrm{P}=$ $0.0025)$.

\section{LIs, Not Specified (LIs-NS)}

Table 3 shows that among patients with rich LIs-NS, the prognostic benefit was apparent when data for ER-patients were pooled with a relapse risk reduction of $75 \%(\mathrm{HR}=$ $0.25 ; 95 \%$ CI, 0.13-0.47; $\mathrm{P}<0.0001)$. For patients with triple-negative tumors, we demonstrated a $73 \%$ reduction in the risk of relapse. However, enough data were not available to examine the effect of LIs-NS in ER+ tumors.

\section{Other LIs Markers}

The analysis showed that rich $\mathrm{CD} 8+$ tumor versus less was associated with $88 \%$ relapse risk reduction $(\mathrm{HR}=0.12$; 95\% CI, 0.04-0.32; P <0.0001) for ER-NS tumors. Data for CD8+ $\mathrm{T}$ cells in ER- tumors were only available from the study of West et al. [35]. It in the latter study, CD8+ rich predicted a $42 \%$ reduction in breast cancer relapse (data not shown). On the other hand, CD3+ rich was not found to be a prognostic variable. Likewise, analysis of FOXP3 rich tumors failed to show a prognostic value in ER-NS disease $(\mathrm{HR}=1.08 ; 95 \% \mathrm{CI}, 0.67-1.73 ; \mathrm{P}=0.76)$.

\section{Anatomical Location for LIs Interpretation}

Analysis of the location of LIs (intratumoral vs stromal vs both intratumoral and stromal) showed that LIs prognosticated DFS for ER-NS, ER-, and HER2- tumors. However, in ER+ tumors, rich LIs did not prognosticate RFS regardless of the location of expression (Table $\mathbf{3}$ ).

\section{ANALYSIS OF OS (TABLE 4)}

Similarly, we first examined the utility of any definition used to qualify rich LIs to prognosticate OS for all patients regardless of their tumor receptors status (ER-NS), only using data derived from multivariate analyses. Data for this pooled measure were abstracted or computed from five studies, showing that rich LIs were associated with a $29 \%$ decrease in mortality $(\mathrm{HR}=0.71 ; 95 \% \mathrm{CI}, 0.63-0.80 ; \mathrm{P}$ $<0.0001)$.

\section{LIs-NS}

Table 4 shows that among patients with rich LIs-NS and ER-NS tumors, those with tumor rich LIs-NS demonstrated a $55 \%$ reduction in the risk of death compared with those with less LIs-NS expression ( $\mathrm{HR}=0.45$; 95\% CI, 0.23-0.87; $\mathrm{P}=0.018)$. The prognostic benefit for ER- tumor only showed a trend with a reduction of death of $73 \%(\mathrm{HR}=0.27$; 95\% CI, 0.07-1.03; $\mathrm{P}=0.055)$. On the other hand, analysis of ER+ tumor showed that LIs-NS was not prognostic.

\section{Other LIs Markers}

Rich CD8+ versus less was associated with a death risk reduction of $24 \%$ for ER-NS tumors combined $(\mathrm{HR}=0.76$; 95\% CI, 0.63-0.92; P =0.0042), 44\% for ER- tumors $(\mathrm{HR}=$ $0.56 ; 95 \%$ CI, 0.39-0.81; $\mathrm{P}=0.0019)$, but was not significant for ER+ tumors. The role of rich CD4+ $\mathrm{T}$ cells was also found to be not significant. Similar to its lack of a prognostic value in RFS analysis, the presence of FOXP3 rich tumor could not prognosticate OS in ER-NS or ER- tumors. 
Table 3. Pooled analysis of hazard ratios of the effects of lymphocyte infiltrates on relapse-free survival (random effects models).

\begin{tabular}{|c|c|c|c|c|c|c|c|c|c|c|}
\hline \multirow{2}{*}{$\begin{array}{l}\text { Lymphocyte } \\
\text { Infiltrates }\end{array}$} & \multirow{2}{*}{ Receptors } & \multirow{2}{*}{ Study } & \multicolumn{3}{|c|}{$\mathrm{HR}^{\mathrm{a}}$ and $95 \% \mathrm{CI}^{\mathrm{b}}$} & \multirow{2}{*}{ P Value } & \multicolumn{3}{|c|}{ Model HR and $95 \%$ CI } & \multirow{2}{*}{$P$ value } \\
\hline & & & HR & Lower & Upper & & HR & Lower & Upper & \\
\hline \multirow[t]{8}{*}{ All LIs ${ }^{\mathrm{c}}$} & ER-NS ${ }^{d}$ & Kim 2012 [24] & 1.00 & 0.61 & 1.63 & 1.00 & 0.48 & 0.30 & 0.77 & 0.0025 \\
\hline & & Loi 2013 [27] & 0.30 & 0.11 & 0.81 & 0.0181 & & & & \\
\hline & & Ma 2012 [28] & 0.04 & 0.01 & 0.16 & $<0.0001$ & & & & \\
\hline & & Mohammed 2012 [31] & 0.31 & 0.13 & 0.74 & 0.0083 & & & & \\
\hline & & Rakha 2009 [33] & 0.67 & 0.53 & 0.85 & 0.0009 & & & & \\
\hline & & West 2013 [35] & 0.65 & 0.40 & 1.06 & 0.0811 & & & & \\
\hline & & Camp 1996 [36] & 0.75 & 0.26 & 2.16 & 0.5943 & & & & \\
\hline & & Rakha 2009 [33] & 0.67 & 0.53 & 0.85 & 0.0009 & & & & \\
\hline \multirow{3}{*}{ LIs-NS $^{\mathrm{e}}$} & ER- & Alexe 2007 [21] & 0.19 & 0.04 & 0.90 & 0.0359 & 0.25 & 0.13 & 0.47 & $<0.0001$ \\
\hline & & Kreike [37] & 0.24 & 0.09 & 0.62 & 0.0035 & & & & \\
\hline & & Loi 2013 [27] & 0.30 & 0.11 & 0.81 & 0.0181 & & & & \\
\hline \multirow[t]{2}{*}{ LIs-NS } & $\mathrm{TN}$ & Kreike [37] & 0.24 & 0.09 & 0.62 & 0.0035 & 0.27 & 0.13 & 0.53 & 0.0002 \\
\hline & & Loi 2013 [27] & 0.30 & 0.11 & 0.81 & 0.0181 & & & & \\
\hline \multirow[t]{2}{*}{ CD8+ } & ER-NS & Kim 2012 [24] & 0.36 & 0.09 & 1.46 & 0.1517 & 0.12 & 0.04 & 0.32 & $<0.0001$ \\
\hline & & Ma 2012 [28] & 0.04 & 0.01 & 0.16 & 0.0000 & & & & \\
\hline \multirow[t]{2}{*}{ CD3+ } & ER-NS & Eiro' 2012 [23] & 0.81 & 0.53 & 1.23 & 0.3265 & 0.80 & 0.54 & 1.19 & 0.27 \\
\hline & & Camp 1996 [36] & 0.75 & 0.26 & 2.16 & 0.5943 & & & & \\
\hline \multirow[t]{2}{*}{ FOXP3 } & ER-NS & Kim 2012 [24] & 1.00 & 0.61 & 1.63 & 1.0000 & 1.08 & 0.67 & 1.73 & 0.76 \\
\hline & & Ma 2012 [28] & 3.08 & 0.49 & 19.26 & 0.2291 & & & & \\
\hline Location & Receptors & & & & & & & & & \\
\hline Tumor & ER+ and ER- & & 0.64 & 0.50 & 0.80 & 0.0001 & 0.94 & 0.91 & 0.97 & $<0.0001$ \\
\hline Stromal & & & 0.94 & 0.88 & 1.00 & 0.0631 & & & & \\
\hline Tumor and stromal & & & 0.68 & 0.58 & 0.78 & $<0.0001$ & & & & \\
\hline Tumor & ER- & & 0.50 & 0.35 & 0.73 & 0.0003 & 0.31 & 0.15 & 0.62 & 0.001 \\
\hline Stroma & & & 0.85 & 0.76 & 0.93 & 0.0010 & & & & \\
\hline Tumor and stromal & & & 0.30 & 0.15 & 0.62 & 0.0011 & & & & \\
\hline Tumor & ER+ & & 1.10 & 0.93 & 1.31 & 0.2799 & 1.01 & 0.96 & 1.06 & 0.78 \\
\hline Stromal & & & 1.00 & 0.95 & 1.05 & 1.0000 & & & & \\
\hline Tumor and stromal & & & 0.89 & 0.44 & 1.80 & 0.7457 & & & & \\
\hline Tumor & HER2- & & 0.80 & 0.69 & 0.93 & 0.0033 & 0.46 & 0.24 & 0.90 & 0.023 \\
\hline Stromal & & & 0.87 & 0.80 & 0.94 & 0.0003 & & & & \\
\hline Tumor and stromal & & & 0.51 & 0.32 & 0.82 & 0.0227 & & & & \\
\hline Method & Receptors & & & & & & & & & \\
\hline Hematoxylin-eosin & All receptors & & 0.80 & 0.71 & 0.90 & $<0.0001$ & 0.64 & 0.54 & 0.77 & $<0.0001$ \\
\hline Immunohistochemistry & All receptors & & 0.64 & 0.54 & 0.77 & $<0.0001$ & & & & \\
\hline
\end{tabular}

ahazard ratio ; ${ }^{b}$ confidence interval; ${ }^{c}$ lymphocyte infiltrates; ${ }^{d}$ estrogen receptors not specified; ${ }^{c}$ lymphocyte infiltrates non-specified.

\section{Anatomical Location for LIs Interpretation}

Analysis of the location of LIs showed that rich LIs prognosticated OS for ER-NS tumors, with the presence of rich LIs in both tumor and stroma. For ER- tumors, rich LIs was associated with a lower risk of death if expressed in the tumors. However, for ER- or ER+ tumors analyzed separately, rich LIs expression was not significant, regardless of its location of expression. For HER2- tumors, rich LIs presence, either in the tumor or in the stroma, was prognostically significant. 
Table 4. Pooled analysis of hazard ratios of the effects of lymphocyte infiltrates on overall survival (random effects models).

\begin{tabular}{|c|c|c|c|c|c|c|c|c|c|c|}
\hline $\begin{array}{l}\text { Lymphocyte } \\
\text { Infiltrates }\end{array}$ & Receptors & Study & \multicolumn{3}{|c|}{$H^{a}{ }^{a}$ and $95 \%$ CI } & P Value & \multicolumn{3}{|c|}{ Model HR and $95 \% \mathrm{CI}^{\mathrm{b}}$} & P Value \\
\hline \multirow[t]{4}{*}{ All LIs ${ }^{\mathrm{c}}$} & ER-NS ${ }^{\mathrm{d}}$ & Lee 2006 [25] & 0.43 & 0.24 & 0.77 & 0.0045 & 0.71 & 0.63 & 0.80 & $\overline{<<0.0001}$ \\
\hline & & Liu 2012 [26] & 0.79 & 0.68 & 0.91 & 0.0015 & & & & \\
\hline & & Ma 2012 & 3.34 & 1.21 & 9.23 & 0.0201 & & & & \\
\hline & & Mahmoud 2011 [29] & 0.55 & 0.38 & 0.78 & 0.0009 & & & & \\
\hline \multirow[t]{4}{*}{ LIs-NS $^{\mathrm{e}}$} & ER-NS & Lee 2006 [25] & 0.43 & 0.24 & 0.77 & 0.0045 & 0.45 & 0.23 & 0.87 & 0.0184 \\
\hline & & Loi 2013 [27] & 1.00 & 0.88 & 1.14 & 1.0000 & & & & \\
\hline & & Mohammed 2012 [31] & 0.13 & 0.07 & 0.24 & $<0.0001$ & & & & \\
\hline & & Rakha 2009 [33] & 0.57 & 0.44 & 0.74 & 0.0045 & & & & \\
\hline LIs-NS & ER- & Calabro 2009 [22] & 0.67 & 0.53 & 0.85 & 0.0012 & 0.27 & 0.07 & 1.03 & 0.055 \\
\hline \multirow{2}{*}{ LIs-NS } & & Loi 2013 [27] & 1.10 & 1.00 & 1.21 & 0.0500 & & & & \\
\hline & & Mohammed 2012 [31] & 0.15 & 0.07 & 0.33 & $<0.0001$ & & & & \\
\hline \multirow[t]{2}{*}{ CD4 } & ER-NS & Ma 2012 [28] & 1.20 & 0.47 & 3.08 & 0.7043 & 1.00 & 0.95 & 1.05 & 0.98 \\
\hline & & Matkowski 2009 [32] & 1.00 & 0.95 & 1.05 & 1.0000 & & & & \\
\hline \multirow[t]{5}{*}{$\mathrm{CD} 8$} & ER-NS & Baker 2011 [13] & 0.88 & 0.77 & 1.01 & 0.0676 & 0.76 & 0.63 & 0.92 & 0.0042 \\
\hline & & Liu 2012 [26] & 0.79 & 0.68 & 0.91 & 0.0015 & & & & \\
\hline & & Ma 2012 [28] & 0.32 & 0.13 & 0.79 & 0.0133 & & & & \\
\hline & & Mahmoud 2011 [29] & 0.55 & 0.38 & 0.78 & 0.0009 & & & & \\
\hline & & Matkowski 2009 [32] & 1.00 & 0.97 & 1.03 & 1.0000 & & & & \\
\hline \multirow{2}{*}{ FOXP3 } & ER - & Mahmoud 2011 [30] & 1.00 & 0.98 & 1.02 & 1.0000 & 1.00 & 0.98 & 1.02 & 1.0000 \\
\hline & & West 2013 [35] & 1.00 & 0.97 & 1.03 & 1.0000 & & & & \\
\hline Location & Receptors & West 2013 [35] & 1.00 & 0.97 & 1.03 & 1.0000 & & & & \\
\hline Tumor & ER+ and ER- & & 0.93 & 0.82 & 1.04 & 0.1908 & 0.80 & 0.69 & 0.94 & 0.005 \\
\hline Stromal & & & 1.01 & 0.91 & 1.12 & 0.8555 & & & & \\
\hline Tumor and stromal & & & 0.80 & 0.69 & 0.93 & 0.0049 & & & & \\
\hline Tumor & ER- & & 0.58 & 0.48 & 0.71 & 0.0000 & 0.79 & 0.58 & 1.07 & 0.13 \\
\hline Stromal & & & 0.85 & 0.72 & 1.00 & 0.0539 & & & & \\
\hline Tumor and stromal & & & 0.79 & 0.58 & 1.07 & 0.1299 & & & & \\
\hline Tumor & $\mathrm{ER}+$ & & 0.98 & 0.80 & 1.18 & 0.8049 & 1.14 & 1.01 & 2.16 & 0.051 \\
\hline Stromal & & & 1.04 & 0.89 & 1.20 & 0.6378 & & & & \\
\hline Tumor and stroma & & & 1.23 & 0.92 & 1.64 & 0.1587 & & & & \\
\hline Tumor & HER2 - & & 0.59 & 0.46 & 0.76 & $<0.0001$ & 0.51 & 0.31 & 0.92 & 0.024 \\
\hline Stromal & & & 0.85 & 0.78 & 0.93 & 0.0003 & & & & \\
\hline Method & Receptors & & 0.57 & 0.44 & 0.72 & $<0.0001$ & & & & \\
\hline Hematoxylin-eosin & All receptors & HE & 0.69 & 0.61 & 0.79 & $<0.0001$ & 0.74 & 0.66 & 0.84 & $<0.0001$ \\
\hline $\begin{array}{l}\text { Immunohistochemis } \\
\text { try }\end{array}$ & All receptors & $\mathrm{IHC}$ & 0.89 & 0.86 & 0.93 & $<0.0001$ & & & & \\
\hline
\end{tabular}

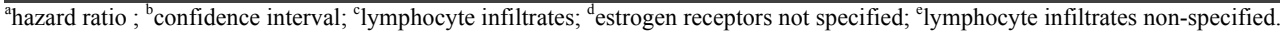




\section{Analysis Based on Methods of LIs Interpretation}

Table 3 shows that designating LIs rich tumors using either hematoxylin and eosin-stained sections (HE) or IHC methods significantly prognosticated RFS with a lower HR for the IHC method (0.64 vs 0.80 , respectively). Similarly, qualifying LIs rich tumors using $\mathrm{HE}$ or IHC methods prognosticated OS, albeit, with a lower HR associated with HE method (Table 4).

\section{ANALYSIS OF pCR (TABLES 5)}

Of 1432 patients in the neoadjuvant setting, the median pCR was $24 \%$ (95\% CI, 13-43\%).

We computed the utility of any classification for rich LIs to predict $\mathrm{pCR}$ for all patients regardless their tumor receptor status using data that used multivariate analyses, and it was found that rich LIs was associated with a $28 \%$ increase in the $\mathrm{pCR}$ rate $(\mathrm{OR}=1.28 ; 95 \% \mathrm{CI}, 1.16-1.42 ; \mathrm{P}<0.0001)$.

Table 5 also shows that among patients with rich LIs-NS, and ER-NS tumors, those with tumors that demonstrated rich LIs-NS had a $27 \%$ higher pCR rate $(\mathrm{OR}=1.27 ; 95 \% \mathrm{CI}$, $1.14-1.40 ; \mathrm{P}=<0.0001)$. Furthermore, among patients with ER- tumors, the presence of rich LIs-NS was associated with an almost seven-fold increase in the $\mathrm{pCR}$ rate $(\mathrm{OR}=6.60$;
95\% CI, 2.27-19.16; $\mathrm{P}=0.0005)$. On the other hand, rich LIs-NS did not predict pCR in HER2+ tumors and there were no sufficient data pertinent to ER+ tumors.

\section{META-REGRESSION ANALYSES (TABLE 6)}

To explain heterogeneity in the pooled estimates, we carried out a series of meta-regression analyses. The dependent variable was the $\ln \mathrm{HR}$ or InOR, weighted for the inverse of variance to perform weighted least-square linear regression. We first conducted a univariate regression analysis including the following variables: median age, study size, median follow-up, receptors status, LIs groups, location of LIs, HE versus IHC for LIs interpretation, retrospective versus prospective design, and blinding versus open/unclear LIs interpretation.

For analysis of RFS, we demonstrated that larger study size was associated with higher HR, while higher percentage of ER- tumors was inversely associated with HR. For OS analysis, retrospective analysis was associated with lower HR, while the use of IHC was associated with higher HR. Table 6 also shows that the heterogeneity in pCR rates was partially explained by a positive relationship between the percentage of ER- tumors and OR.

Table 5. Pooled analysis of odds ratios of the effects of lymphocyte infiltrates on complete pathological response (random effects models).

\begin{tabular}{|c|c|c|c|c|c|c|c|c|c|c|}
\hline \multirow{2}{*}{ LI } & \multirow{2}{*}{ Receptors } & \multirow{2}{*}{ Study } & \multicolumn{3}{|c|}{$\mathrm{HR}^{\mathrm{a}}$ and $95 \% \mathrm{CI}$} & \multirow{2}{*}{ P Value } & \multicolumn{3}{|c|}{ Model HR and $95 \% \mathrm{CI}^{\mathrm{b}}$} & \multirow{2}{*}{ P value } \\
\hline & & & HR & Lower & Upper & & HR & Lower & Upper & \\
\hline \multirow[t]{4}{*}{ LIs-NS $^{c}$} & ER-NS $^{\mathrm{d}}$ & Denkert 2010 [38] & 1.38 & 1.07 & 1.77 & 0.0115 & 1.27 & 1.14 & 1.40 & $<0.0001$ \\
\hline & & Denkert 2010 [38] & 1.21 & 1.08 & 1.35 & 0.0008 & & & & \\
\hline & & Yamaguchi 2012 [40] & 4.70 & 2.20 & 10.05 & 0.0001 & & & & \\
\hline & & West 2011 [34] & 1.21 & 0.52 & 2.81 & 0.6578 & & & & \\
\hline \multirow[t]{2}{*}{ LIs-NS } & ER- & Alexe 2007 [21] & 8.33 & 0.32 & 216.35 & 0.20 & 6.60 & 2.27 & 19.16 & 0.0005 \\
\hline & & West 2011 [34] & 6.42 & 2.08 & 19.82 & 0.0012 & & & & \\
\hline \multirow[t]{3}{*}{ LIs-NS } & HER2+ & Alexe 2007 [21] & 8.33 & 0.32 & 216.35 & 0.2019 & 1.64 & 0.79 & 3.44 & 0.19 \\
\hline & & Ono 2012 [39] & 3.72 & 0.67 & 20.63 & 0.1330 & & & & \\
\hline & & West 2011 [34] & 1.21 & 0.52 & 2.81 & 0.6578 & & & & \\
\hline
\end{tabular}

Table 6. Results of the multivariate meta-regression analyses (random effects models).

\begin{tabular}{|c|c|c|c|c|}
\hline Model & Model $\mathbf{R}^{2}$ & Covariates & Meta-Regression $\beta$ coefficient (SE) & $P$ Value \\
\hline \multicolumn{5}{|l|}{ Relapse-free survival } \\
\hline Pooled hazard ratio & & Percentage of ER- tumors & $-0.025(0.002)$ & 0.004 \\
\hline \multicolumn{5}{|l|}{ Overall survival } \\
\hline \multicolumn{5}{|c|}{ Complete pathological response } \\
\hline Pooled odds ratio & 0.52 & Percentage of ER- tumors & $1.45(0.33)$ & $<0.0001$ \\
\hline
\end{tabular}




\section{DISCUSSION}

The present meta-analysis, including a large cohort of 16,097 patients reported from 21 studies, provided quantitative estimates of the prognostic and predictive values of LIs on breast cancer outcome. Using data that were based on multivariate analyses in the original studies for patients with unspecified receptors status showed that rich LIs was associated with $52 \%$ and $29 \%$ reduction in the risk of relapse and death, respectively. Moreover, rich LIs predicted a $28 \%$ increase in the $\mathrm{pCR}$ rate.

In various subgroup analyses, it was evident that the prognostic and predictive utility of rich LIs was almost restricted to patients with ER- tumors. For instance, rich LIsNS predicted a $75 \%$ and a $73 \%$ reduction in the risk of relapse and death, respectively, in patients harboring ERtumors or having triple negative disease, while no such advantage was seen among those with ER+ tumors. More impressive, was the seven-fold increase in $\mathrm{pCR}$ rate associated with rich LIs-NS among patients with ERtumors. While, it is well known that LIs have been shown to predominate in ER- tumors [7], the biological process that may explain the preferential prognostic benefit of rich LIs for ER- but not for ER+ tumors is unclear.

In clinical practice, significant heterogeneity in treatment response may occur in tumors with identical clinicopathological characteristics [41], therefore, it may not be utterly unexpected for two distinctively different breast cancer subtypes to respond differently to immune stimulation. Therefore, the clinical utility of LIs appears to be subtype-specific and varies depending on the histologic characteristics of breast cancer. Even within a seemingly uniform cohort of 186 ER- breast tumors, there was a demonstrated heterogeneity in clinical outcomes, apparently related to the variability in the expression levels of immune response pathway genes [42].

LIs demonstrated a prognostic utility for HER-2- but not for HER2+ tumors. The exact elucidation for this observation was not clear due to the limited data that reported HER2+ disease. This may likely be related to the fact that LIs in HER2+ tumors have a preponderance of macrophages, whereas LIs in HER2- tumors are composed mostly of T cells [43].

Of all other lymphocyte markers, tumors expressing excess CD8+ T cells showed relapse and death risk reduction of $88 \%$ and $24 \%$, respectively. This prognostic utility was shown among patients with ER- and ER+ tumors when grouped together. The prognostic value of rich CD8+ is in keeping with the fact that most LIs in breast cancer are CD8 $+\mathrm{T}$ cells $[7,44]$ and considered as cytotoxic effectors able to contribute to the better clinical outcome associated with their overexpression $[45,46]$. On the contrary, neither FOXP3 expression, nor rich $\mathrm{CD} 3+$ or rich $\mathrm{CD} 4+$ demonstrated prognostic utility.

Analysis of the location of designating rich LIs expression prognosticated RFS for ER-NS, ER-, or HER2tumors regardless of the location of expression. However, it appears that intratumoral expression is more valuable and the results were more consistent. Although there were some numerical differences in the estimate of pooled HRs using either HE or IHC for qualifying LIs, both methods significantly prognosticated RFS and OS.

The present meta-analysis has several limitations. First, some of the included studies had several quality and design shortcomings. For example, only three studies were prospective, and in only nine, the assessors of LIs were blinded from patients' outcomes. Such open interpretation may have its own bias attributable to knowing the clinical outcome. Yet, the consistent patterns of the pooled measures may suggest that the effect of unblended interpretation was minimal. Second, while testing for publication bias was not significant for studies examining the prognostic clinical utility of rich LIs, the predictive advantage of rich LIs in the neoadjuvant setting demonstrated significant publication bias. Nevertheless, this limitation represents the scarcity of the current available evidence.

Third, different studies have used different qualification criteria to determine LIs. Nonetheless, grouping methods into either HE- or IHC-based clearly showed that both methods were significantly able to prognosticate RFS and OS. Moreover, the large population of patients included in this meta-analysis probably minimized such diversity.

Fourth, the current meta-analysis could not address the potential interactions between the clinical utility of rich LIs and other relevant factors such as tumor grade, nodal status, or adjuvant therapy. Unfortunately, the included studies did not provide sufficient therapy details to permit such analysis. In our meta-regression analyses, the limitation of the available data in the original reports was restrictive as we were only able to model the following variables: median age, study size, median follow-up, receptors status, LIs groups, location of LIs, HE versus IHC for LIs interpretation, retrospective versus prospective design, and blinding versus open/unclear LIs interpretation.

Fifth, inherent to meta-analyses, the included population from individual studies demonstrated clinicopathological differences. Nonetheless, almost all patients had nonmetastatic or locally advanced disease; IDC was the most common histologic subtype; and the included studies had patients with comparable median ages. To explore heterogeneity, we conducted a series of meta-regression analyses to assess the impact of several explanatory variables that may have contributed to the statistical heterogeneity. The meta-regression for RFS showed that study size was positively associated with HR, while the percentage of ERtumors showed an inverse association. For OS analysis, retrospective analysis was associated with a lower HR, while the use of IHC was associated with a higher HR. In the neoadjuvant setting, a positive association was shown between the percentage of ER- tumors and OR.

\section{CONCLUSION}

In conclusion, our meta-analysis that included a large population of patients reported from 21 studies showed that LIs significantly prognosticated RFS and OS and successfully predicted the pCR rate. We demonstrated the clinical utility mainly among patients with ER- tumors, regardless of the use of LIs-NS or CD8+ T cell markers to qualify LIs. On the other hand, no apparent clinical value was demonstrated among patients with ER+ tumors. The 
clinical utility of rich LIs should serve as an impetus for future clinical trials designed to integrate novel immune therapy with conventional therapeutic modalities among patients with breast cancer. Future research may also help identifying those who are most likely to benefit from immune-modulating therapies.

\section{CONFLICT OF INTEREST}

The authors confirm that this article content has no conflict of interest.

\section{ACKNOWLEDGEMENTS}

Declared none.

\section{REFERENCES}

[1] Zitvogel L, Apetoh L, Ghiringhelli F, Kroemer G. Immunological aspects of cancer chemotherapy. Nat Rev Immunol 2008; 8: 59-73.

[2] Apetoh L, Ghiringhelli F, Tesniere A, et al. The interaction between HMGB1 and TLR4 dictates the outcome of anticancer chemotherapy and radiotherapy. Immunol Rev 2007; 220: 47-59.

[3] Demaria S, Volm MD, Shapiro RL, et al. Development of tumorinfiltrating lymphocytes in breast cancer after neoadjuvant paclitaxel chemotherapy. Clin Cancer Res 2001; 7: 3025-30.

[4] Zhang L, Conejo-Garcia JR, Katsaros D, et al. Intratumoral T cells, recurrence, and survival in epithelial ovarian cancer. N Engl J Med 2003; 348: 203-13.

[5] Galon J, Costes A, Sanchez-Cabo F, et al. Type, density, and location of immune cells within human colorectal tumors predict clinical outcome. Science 2006; 313: 1960-4.

[6] Wolf D, Wolf AM, Rumpold $\mathrm{H}$, et al. The expression of the regulatory $\mathrm{T}$ cell-specific forkhead box transcription factor FoxP3 is associated with poor prognosis in ovarian cancer. Clin Cancer Res 2005; 11: 8326-31.

[7] Whitford P, Mallon EA, George WD, Campbell AM. Flow cytometric analysis of tumour infiltrating lymphocytes in breast cancer. Br J Cancer 1990; 62: 971-5.

[8] Nixon AJ, Schnitt SJ, Gelman R, et al. Relationship of tumor grade to other pathologic features and to treatment outcome of patients with early stage breast carcinoma treated with breast-conserving therapy. Cancer 1996; 78: 1426-31.

[9] Droeser R, Zlobec I, Kilic E, et al. Differential pattern and prognostic significance of $\mathrm{CD} 4+$, FOXP3+ and IL-17+ tumor infiltrating lymphocytes in ductal and lobular breast cancers. BMC Cancer 2012; 12: 134

[10] Livasy CA, Karaca G, Nanda R, et al. Phenotypic evaluation of the basal-like subtype of invasive breast carcinoma. Mod Pathol 2006; 19: 264-71.

[11] Lakhani SR. The pathology of familial breast cancer: Morphological aspects. Breast Cancer Res 1999; 1: 31-5.

[12] Tamiolakis D, Simopoulos C, Cheva A, et al. Immunophenotypic profile of tumor infiltrating lymphocytes in medullary carcinoma of the breast. Eur J Gynaecol Oncol 2002; 23: 433-6.

[13] Baker K, Lachapelle J, Zlobec I, Bismar TA, Terracciano L, Foulkes WD. Prognostic significance of CD8+ T lymphocytes in breast cancer depends upon both oestrogen receptor status and histological grade. Histopathology 2011; 58: 1107-16.

[14] Tierney JF, Stewart LA, Ghersi D, Burdett S, Sydes MR. Practical methods for incorporating summary time-to-event data into metaanalysis. Trials 2007; 8: 16.

[15] Parmar MK, Torri V, Stewart L. Extracting summary statistics to perform meta-analyses of the published literature for survival endpoints. Stat Med 1998; 17: 2815-34.

[16] Higgins JP, Thompson SG. Quantifying heterogeneity in a metaanalysis. Stat Med 2002; 21: 1539-58.

[17] Higgins JP, Thompson SG, Deeks JJ, Altman DG. Measuring inconsistency in meta-analyses. BMJ 2003; 327: 557-60.

[18] DerSimonian R, Laird N. Meta-analysis in clinical trials. Control Clin Trials 1986; 7: 177-88.
[19] Donders AR, van der Heijden GJ, Stijnen T, Moons KG. Review: a gentle introduction to imputation of missing values. J Clin Epidemiol 2006; 59: 1087-91

[20] Egger M, Davey Smith G, Schneider M, Minder C. Bias in metaanalysis detected by a simple, graphical test. BMJ 1997; 315: 62934.

[21] Alexe G, Dalgin GS, Scanfeld D, et al. High expression of lymphocyte-associated genes in node-negative HER2+ breast cancers correlates with lower recurrence rates. Cancer Res 2007; 67: 10669-76.

[22] Calabro A, Beissbarth T, Kuner R, et al. Effects of infiltrating lymphocytes and estrogen receptor on gene expression and prognosis in breast cancer. Breast Cancer Res Treat 2009; 116: 6977.

[23] Eiro N, Pidal I, Fernandez-Garcia B, et al. Impact of CD68/(CD3+CD20) ratio at the invasive front of primary tumors on distant metastasis development in breast cancer. PLoS One 2012; 7: e52796.

[24] Kim ST, Jeong H, Woo OH, et al. Tumor-infiltrating lymphocytes, tumor characteristics, and recurrence in patients with early breast cancer. Am J Clin Oncol 2012; 36: 224-31.

[25] Lee AH, Gillett CE, Ryder K, Fentiman IS, Miles DW, Millis RR. Different patterns of inflammation and prognosis in invasive carcinoma of the breast. Histopathology 2006; 48: 692-701.

[26] Liu S, Lachapelle J, Leung S, Gao D, Foulkes WD, Nielsen TO. CD8+ lymphocyte infiltration is an independent favorable prognostic indicator in basal-like breast cancer. Breast Cancer Res 2012; 14: R48

[27] Loi S, Sirtaine N, Piette F, et al. Prognostic and predictive value of tumor-infiltrating lymphocytes in a phase III randomized adjuvant breast cancer trial in node-positive breast cancer comparing the addition of docetaxel to doxorubicin with doxorubicin-based chemotherapy: BIG 02-98. J Clin Oncol 2013; 31: 860-7.

[28] Ma C, Zhang Q, Ye J, et al. Tumor-infiltrating gammadelta lymphocytes predict clinical outcome in human breast cancer. J Immunol 2012; 189: 5029-36.

[29] Mahmoud SM, Paish EC, Powe DG, et al. Tumor-infiltrating CD8+ lymphocytes predict clinical outcome in breast cancer. J Clin Oncol 2011; 29: 1949-55.

[30] Mahmoud SM, Paish EC, Powe DG, et al. An evaluation of the clinical significance of FOXP3+ infiltrating cells in human breast cancer. Breast Cancer Res Treat 2011; 127: 99-108.

[31] Mohammed ZM, Going JJ, Edwards J, Elsberger B, Doughty JC, McMillan DC. The relationship between components of tumour inflammatory cell infiltrate and clinicopathological factors and survival in patients with primary operable invasive ductal breast cancer. Br J Cancer 2012; 107: 864-73.

[32] Matkowski R, Gisterek I, Halon A, et al. The prognostic role of tumor-infiltrating CD4 and CD8 T lymphocytes in breast cancer. Anticancer Res 2009; 29: 2445-51.

[33] Rakha EA, Aleskandarany M, El-Sayed ME, et al. The prognostic significance of inflammation and medullary histological type in invasive carcinoma of the breast. Eur J Cancer 2009; 45: 1780-7.

[34] West NR, Milne K, Truong PT, Macpherson N, Nelson BH, Watson PH. Tumor-infiltrating lymphocytes predict response to anthracycline-based chemotherapy in estrogen receptor-negative breast cancer. Breast Cancer Res 2011; 13: R126.

[35] West NR, Kost SE, Martin SD, et al. Tumour-infiltrating FOXP3(+) lymphocytes are associated with cytotoxic immune responses and good clinical outcome in oestrogen receptor-negative breast cancer. Br J Cancer 2013; 108: 155-62.

[36] Camp BJ, Dyhrman ST, Memoli VA, Mott LA, Barth RJ, Jr. In situ cytokine production by breast cancer tumor-infiltrating lymphocytes. Ann Surg Oncol 1996; 3: 176-84.

[37] Kreike B, van Kouwenhove M, Horlings H, et al. Gene expression profiling and histopathological characterization of triplenegative/basal-like breast carcinomas. Breast Cancer Res 2007; 9 : R65.

[38] Denkert C, Loibl S, Noske A, et al. Tumor-associated lymphocytes as an independent predictor of response to neoadjuvant chemotherapy in breast cancer. J Clin Oncol 2010; 28: 105-13.

[39] Ono M, Tsuda H, Shimizu C, et al. Tumor-infiltrating lymphocytes are correlated with response to neoadjuvant chemotherapy in triplenegative breast cancer. Breast Cancer Res Treat 2012; 132: 793 805 . 
[40] Yamaguchi R, Tanaka M, Yano A, et al. Tumor-infiltrating lymphocytes are important pathologic predictors for neoadjuvant chemotherapy in patients with breast cancer. Hum Pathol 2012; 43: 1688-94.

[41] Anim JT, John B, Abdulsathar SS, et al. Relationship between the expression of various markers and prognostic factors in breast cancer. Acta Histochem 2005; 107: 87-93.

[42] Teschendorff AE, Miremadi A, Pinder SE, Ellis IO, Caldas C. An immune response gene expression module identifies a good prognosis subtype in estrogen receptor negative breast cancer. Genome Biol 2007; 8: R157.
[43] Pupa SM, Bufalino R, Invernizzi AM, et al. Macrophage infiltrate and prognosis in c-erbB-2-overexpressing breast carcinomas. J Clin Oncol 1996; 14: 85-94.

[44] Rubbert A, Manger B, Lang N, Kalden JR, Platzer E. Functional characterization of tumor-infiltrating lymphocytes, lymph-node lymphocytes and peripheral-blood lymphocytes from patients with breast cancer. Int J Cancer 1991; 49: 25-31.

[45] Bertucci F, Finetti P, Cervera N, Maraninchi D, Viens P, Birnbaum D. Gene expression profiling and clinical outcome in breast cancer. OMICS 2006; 10: 429-43.

[46] Wong PY, Staren ED, Tereshkova N, Braun DP. Functional analysis of tumor-infiltrating leukocytes in breast cancer patients. J Surg Res 1998; 76: 95-103.

(C) Ibrahim et al.; Licensee Bentham Open.

This is an open access article licensed under the terms of the Creative Commons Attribution Non-Commercial License (http://creativecommons.org/licenses/by-nc/ 3.0/) which permits unrestricted, non-commercial use, distribution and reproduction in any medium, provided the work is properly cited. 